\title{
BMJ Open Referral patterns after a seizure admission in an English region: an opportunity for effective intervention? An observational study of routine hospital data
}

\author{
Ruth Grainger, ${ }^{1,2}$ Michael Pearson, ${ }^{2}$ Peter Dixon, ${ }^{2}$ Elizabeth Devonport, ${ }^{2}$ \\ Michelle Timoney, ${ }^{3}$ Keith Bodger, ${ }^{4,5}$ Jamie Kirkham, ${ }^{6}$ Anthony Marson ${ }^{2}$
}

To cite: Grainger $\mathrm{R}$, Pearson M, Dixon P, et al. Referral patterns after a seizure admission in an English region: an opportunity for effective intervention? An observational study of routine hospital data. BMJ Open 2016;6:e10100.

doi:10.1136/bmjopen-2015010100

- Prepublication history and additional material is available. To view please visit the journal (http://dx.doi.org/ 10.1136/bmjopen-2015010100).

Received 24 September 2015 Revised 3 November 2015 Accepted 10 November 2015

\section{CrossMark}

For numbered affiliations see end of article.

\section{Correspondence to}

Professor Michael Pearson; michael.pearson@liverpool. ac.uk

\section{ABSTRACT}

Objectives: To identify emergency seizure admissions to hospital and their subsequent access to specialist outpatient services.

Design: Algorithmic analysis of anonymised routine hospital data over 7 years using specialist follow-up by 3 months as the target outcome.

Population: All adults resident in Merseyside and Cheshire, England.

Main Outcomes: Whether, and when, access to the specialist advice that might prevent further admissions was offered.

Results: $1.4 \%$ of all emergency medical admissions are as a result of seizure. In the following 12 months $35 \%$ were readmitted and experienced a mean of 2.3 emergency department visits. Only $27 \%$ (48\% of those already known to specialists and $13 \%$ of those not known) were offered appointments. Subsequent attendance at a specialist clinic is more likely if already known to a clinic, if aged $<35$ years, if female, or required a longer spell in hospital. Extrapolation from other work suggests 100000 bed days per annum could be saved.

Conclusions: Most seizure admissions are not being referred for the help that could prevent future admissions. The majority of those that are referred are not seen within an appropriate time frame. Our service structures are not providing an optimum service for people with epilepsy.

\section{INTRODUCTION}

Many patients with epilepsy $(70 \%)$ are seizure free with or without medication, seizure freedom is associated with a better quality of life, however, up to $30 \%$ have persistent seizures and require specialist management. ${ }^{12}$ 'Specialist' usually means neurologist because of the wide range of therapeutic options, yet most seizures present to emergency

\section{Strengths and limitations of this study}

- The National Audit of Seizure management in Hospitals (NASH) audit showed that the care of people presenting to hospital following a seizure is variable and that only a quarter of patients were being seen in specialist clinics. One report suggests that length of stay could be halved and readmissions reduced by $80 \%$.

- Using different methods this paper confirms with larger numbers over 7 years, that within 3 months, only $27 \%$ of seizure admissions are reaching the specialist advice that could improve their outcome.

- There is a substantial disconnect between the needs of the patients attending emergency services/secondary hospitals and their access to neurology specialists.

departments (EDs) or acute medical units without neurologists, and this paper examines the patient pathways after presenting with a seizure to hospital, and how often patients do get to specialist care.

The second National Audit of Seizure management in Hospitals (NASH) ${ }^{3}$ described over 4500 attendances at EDs following a seizure, and showed that $66 \%$ of patients with known epilepsy were on either monotherapy $(48 \%)$ or no therapy $(18 \%)$, that care at hospital was variable, and that only a quarter went on to receive specialist advice. This suggests that opportunities to prevent another seizure are being missed.

Medical emergency admissions (ie, nonsurgical) are rising across the $\mathrm{UK}^{4}$ and are more than twice as likely among the most deprived population decile (vs mean deprivation) implying challenges that are medical and social. ${ }^{5}$ Most acute hospitals receiving 
seizure admissions rely on visiting, rather than fulltime, neurology specialists on site, so there are particular organisational challenges getting seizure patients to specialists. A recent report ${ }^{6}$ suggests that this matters and described how, from a similar baseline, an active process of early specialist review halved days in hospital and reduced readmissions by $80 \%$.

This analysis of the hospital admission data for Merseyside and Cheshire was performed to provide data to enable more effective planning of seizure services and asked whether:

- The numbers presenting with seizures were consistent and how they compared with trends for other medical emergency presentations,

- Readmission rates were high and how often patients visited hospital EDs,

- Particular factors affected access to specialist help.

\section{METHODS}

The Hospital Episodes Statistics (HES) data, for the nine hospitals within Cheshire and Merseyside, contains information on hospital admissions, ED attendances, and outpatient clinic visits. It includes the Index of Multiple Deprivation (IMD) based on home address and either death or discharge details. At discharge, coders working to standard methods create a list of up to 20 International Classification of Diseases, 10th Revision (ICD-10) diagnoses ${ }^{7}$ but this does not clarify when a given condition was the prime cause or merely a comorbidity. We have created an algorithm based on knowledge of disease behaviour, clinical pathways, and clinician feedback, using multiple diagnoses from the ICD-10 list to select those where a seizure was likely to be the prime reason for admission.

Inclusion criteria: All emergency admissions to the major medical specialties (not attendances), that were primarily related to presentation with a seizure, in the 7 year period 2006-2013, ie,

- Method of admission was emergency (excluding day and elective cases) AND

- Under care of the major medical specialities (cardiology, respiratory, neurology, etc) AND

- A seizure admission was defined from the discharge diagnosis codes:

- An epilepsy code (G40, G41) in the first diagnosis position (P1) OR

- An epilepsy code second or third in the list (AND a supportive symptom or condition code in P1).

For each admission, we recorded the associated readmissions, ED attendances and neurological (code 400) clinic attendances in the year prior, and the year after. To be sure that we were not missing outpatient data, we confirmed with the service that all neurology clinics had been included, whether occurring locally or in the regional centre. Details of the coding lists, and how they were applied, are available in an online supplementary appendix and available from authors.
For analysis we split patients into two groups who:

A. Had been seen in a neurology clinic in the preceding year (ie, are under active follow-up) (group A),

B. B Had not been seen (ie, currently unknown to neurologists)-representing either suspected first seizures or cases not in active follow-up (group B).

The 7-year data were used to examine differences among hospital sites and trends over time.

Comparisons are by simple $\chi^{2}$, t, or Spearman Rank tests as appropriate.

Finally, we examined the likelihood of being offered a clinic appointment within 3 months with a multiple logistic regression with age groups (15-34, 35-54, 55-74 and $>75$ ), IMD (as quintiles), comorbidity (Charlson Index ${ }^{8}$ ) groups of $0,1-2$ and $>2$ points), sex, whether discharged to a nursing home, whether they had had a clinic appointment in the previous year, an admission or ED attendance in prior year, hospital stay greater than the median, and hospital attended as dependent variables. We excluded those who died in hospital.

\section{RESULTS}

\section{Cohort summary and changes over time}

There were 129933 emergency admissions in 91508 people per year, with numbers increasing by $2.7 \%$ per annum in line with national trends. ${ }^{4}$ There were 1767 seizure admissions/year (in 1020 patients) representing $1.36 \%$ (interhospital range 1.2-1.6\%) of all emergency medical admissions-a proportion that was constant over the 7 years. Table 1 shows that compared with admission for other reasons, seizure admissions were younger (mean age 55 v 66 years), included more males, and had a shorter length of stay, but were of similar deprivation backgrounds. Other than the rising trend in overall admissions, the patterns in each of the years were similar and so no further between-year comparisons are presented. We present analysis by admission, which includes multiple admissions for some patients. Results are similar to those using the first admission per individual.

\section{Patients known, or not known, to the specialist service and interhospital variability}

Table 2 subdivides patients into those who had had a neurology clinic appointment in the prior year (group A), and those who had not (group B) for the central 5 years to include a full year of other activity before and after. There were no significant differences in age, gender, deprivation or admission/clinic rates in the 5 -year cohort versus the 7-year cohort.

Compared with group A, group B patients were older (mean age 59 vs 47 years), had longer lengths of stay, were more likely to be discharged to nursing home care, and included more in-hospital deaths $(3.7 \%$ vs $1.0 \%)$, (all $\mathrm{p}<0.001$ ). But they were less likely to come from deprived areas.

Both groups showed similar high numbers of attendances at the ED in the year before the index admission. 
Table 1 Comparison of mean numbers of seizure admissions to all emergency medical admissions, with the ranges across the nine hospitals

\begin{tabular}{|c|c|c|c|c|}
\hline & $\begin{array}{l}\text { All emergency medical } \\
\text { admissions }\end{array}$ & $\begin{array}{l}\text { Range (lowest and } \\
\text { highest values for } \\
\text { individual hospitals } \\
\text { in the region) }\end{array}$ & $\begin{array}{l}\text { Emergency } \\
\text { admissions due to a } \\
\text { seizure }\end{array}$ & $\begin{array}{l}\text { Range (lowest and } \\
\text { highest values for } \\
\text { individual hospitals } \\
\text { in the region) }\end{array}$ \\
\hline Mean admissions/year & 129933 & $5991-23894$ & 1767 & $68-381$ \\
\hline \multirow{2}{*}{ Mean individuals/year } & 91508 & $5116-15375$ & 1020 & 214-864 \\
\hline & 39.1 per 1000 per annum & $\mathrm{n} / \mathrm{a}$ & 0.4 per 1000 per annum & $\mathrm{n} / \mathrm{a}$ \\
\hline Mean age (years (SD)) & $66(19.3)$ & $62.7-84.1$ & $55(20)$ & $51.4-59.3$ \\
\hline Sex (\% male) & 46.8 & $46.0-48.7$ & 57.7 & $44.3-60.9$ \\
\hline $\begin{array}{l}\text { Median length of stay } \\
\text { (days) }\end{array}$ & 3 IQR 1-7 & $1-4$ & 2 IQR 1-6 & $1-3$ \\
\hline $\begin{array}{l}\text { Mean length of stay } \\
\text { (days) (SD)) }\end{array}$ & $8.0(14.3)$ & $6.5-9.1$ & $5.7(11.5)$ & $3.5-6.8$ \\
\hline Mean IMD rank (SD) & 10400 (9809) & $5266-21108$ & 10869 (9810) & $5437-19954$ \\
\hline
\end{tabular}

The mean figures hide a skewed dispersion such that $17 \%$ (group A) and 9\% (group B) had more than six recorded visits. The pattern of frequent ED visits persists in the year after.

The proportion offered a specialist clinic appointments was less than half in group A and only $11 \%$ in group B. Of these, $14 \%$ and $12 \%$ respectively failed to attend. The interhospital range is moderate, but the low rate of access to specialist assessment is consistently different across hospitals at all time points (figure 1).

We cannot tell how many of the 3066 group A patients (34.6\%) would have had planned appointments as part of their routine care, but if $80 \%$ were offered a 6 month follow-up that could account for a $40 \% 3$ month clinic rate. Similarly we do not know how many of the 5806 group B patients were patients for whom this was the first known seizure and should have been seen within 2 weeks, or were patients with known epilepsy but outside of specialist follow-up.

Table 3 builds on table 2 by subdividing the groups according to whether or not they were offered an appointment at a neurology clinic within 3 months of their emergency admission. There were no significant differences in age, gender, deprivation or admission/

Table 2 Proportion of patients offered a neurology appointment following the acute admission according to whether or not they were current attenders at the specialist neurology clinic

\begin{tabular}{|c|c|c|c|c|}
\hline & $\begin{array}{l}\text { Group A } \\
\text { Current attenders } \\
(n=3066)\end{array}$ & $\begin{array}{l}\text { Range of means } \\
\text { across hospitals }\end{array}$ & $\begin{array}{l}\text { Group B } \\
\text { No recent OPD } \\
(n=5806)\end{array}$ & $\begin{array}{l}\text { Range of means } \\
\text { across hospitals }\end{array}$ \\
\hline Mean age (years (SD)) & 47 & $44-50$ & $59^{*}$ & $54-64$ \\
\hline Sex (\% male) & 55.6 & $44-57$ & 55.9 & $42-59$ \\
\hline Mean IMD rank & 9773 & 5689-20 529 & $11296^{*}$ & $5386-19765$ \\
\hline Mean length of stay (days) & 4.6 & $3.0-6.2$ & $6.2^{*}$ & $3.7-7.7$ \\
\hline $\begin{array}{l}\text { Mean number of ED attendances in the year } \\
\text { preceding the acute admission }\end{array}$ & 3.6 & $2.6-4.4$ & $2.6^{*}$ & $0.9-4.4$ \\
\hline Discharged to nursing home (\%) & 3.5 & $0-5.3$ & $9.0^{*}$ & $0-11.7$ \\
\hline Died in hospital (\%) & 1.0 & $0-2.1$ & $3.7^{*}$ & $1.5-5$ \\
\hline $\begin{array}{l}\text { Mean number of ED attendances in the year } \\
\text { following the acute admission }\end{array}$ & 2.6 & $1.6-4.0$ & $2.0^{*}$ & $1.6-4.0$ \\
\hline Mean yearly readmission rate (\%) & 43.2 & $29-44.6$ & $31.9^{*}$ & $20.8-33.4$ \\
\hline $\begin{array}{l}\text { Patients offered specialist clinic within } \\
2 \text { weeks (\%) (SD) }\end{array}$ & $11(3)$ & $4-15$ & $2(1)^{*}$ & $1-2$ \\
\hline $\begin{array}{l}\text { Patients offered specialist clinic within } \\
3 \text { months (\%) (SD) }\end{array}$ & $48(7)$ & $37-62$ & $11(2)^{\star}$ & $9-14$ \\
\hline $\begin{array}{l}\text { Patients offered specialist clinic within } \\
12 \text { months (\%) (SD) }\end{array}$ & $78(8)$ & $62-90$ & $21(4)^{\star}$ & $17-27$ \\
\hline \multicolumn{5}{|c|}{$\begin{array}{l}\text { Mean data for } 5 \text { years for region as a whole and then the range across individual hospitals. } \\
\text { *Group } B \text { is significantly different }(p<0.01) \text { to Group } A \text {. } \\
\text { Group } B \text { is significantly different from Group A for all variables except gender. }\end{array}$} \\
\hline
\end{tabular}




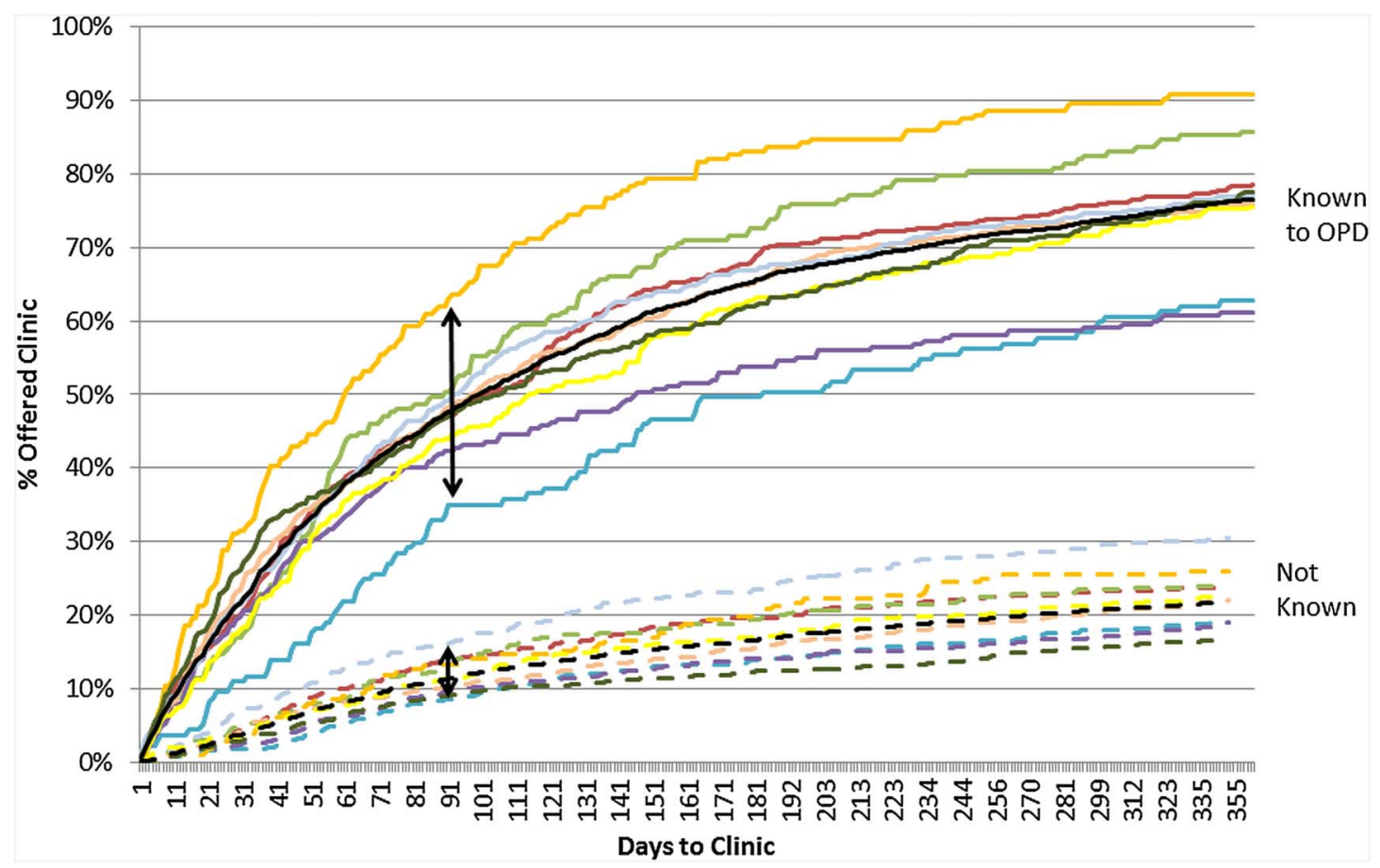

Figure 1 Cumulative percentage of patients from each hospital who were offered outpatient specialist appointments according to whether they had been current attenders (upper set of lines) or not (lower group). The arrows describe the interhospital range at the point used for the regression analysis (OPD, outpatient department).

clinic rates in the 5-year cohort versus the 7-year period. The table describes the whole cohort rather than interhospital differences.

Univariate analysis showed that an appointment was more likely in both groups if patients were younger
( $p<0.001)$, had a shorter length of stay $(\mathrm{p}<0.001)$, had fewer co morbidities, or were female. There was a very weak association with less deprivation. High ED attendance rates (before or after) and readmission rates were not predictive, but those discharged to a nursing care

Table 3 Comparison of patients according to whether or not they were offered a clinic appointment within 3 months (whole cohort-rather than interhospital differences)

\begin{tabular}{|c|c|c|c|c|}
\hline & $\begin{array}{l}\text { Group A } \\
\text { Current attenders } \\
(n=3066)\end{array}$ & $\begin{array}{l}\text { Range of means } \\
\text { across hospitals }\end{array}$ & $\begin{array}{l}\text { Group B } \\
\text { No recent } \\
\text { OPD }(n=5806)\end{array}$ & $\begin{array}{l}\text { Range of means } \\
\text { across hospitals }\end{array}$ \\
\hline Mean Age (years (SD)) & 47 & $44-50$ & $59^{*}$ & $54-64$ \\
\hline Sex (\% male) & 55.6 & $44-57$ & 55.9 & $42-59$ \\
\hline Mean IMD rank & 9773 & $5689-20529$ & $11296^{\star}$ & $5386-19765$ \\
\hline Mean Length Of Stay (days) & 4.6 & $3.0-6.2$ & $6.2^{*}$ & $3.7-7.7$ \\
\hline $\begin{array}{l}\text { Mean number of ED attendances in the year } \\
\text { preceding the acute admission }\end{array}$ & 3.6 & 2.6-4.4 & $2.6^{*}$ & $0.9-4.4$ \\
\hline Discharged to nursing home (\%) & 3.5 & $0-5.3$ & $9.0^{*}$ & $0-11.7$ \\
\hline Died in hospital (\%) & 1.0 & $0-2.1$ & $3.7^{*}$ & $1.5-5$ \\
\hline $\begin{array}{l}\text { Mean number of ED attendances in the year } \\
\text { following the acute admission }\end{array}$ & 2.6 & $1.6-4.0$ & $2.0^{*}$ & $1.6-4.0$ \\
\hline Mean yearly readmission rate (\%) & 43.2 & $29-44.6$ & $31.9^{*}$ & $20.8-33.4$ \\
\hline $\begin{array}{l}\text { Patients offered specialist clinic within } \\
2 \text { weeks (\%) (SD) }\end{array}$ & $11(3)$ & $4-15$ & $2(1)^{*}$ & $1-2$ \\
\hline $\begin{array}{l}\text { Patients offered specialist clinic within } \\
3 \text { months (\%) (SD) }\end{array}$ & $48(7)$ & $37-62$ & $11(2)^{\star}$ & $9-14$ \\
\hline $\begin{array}{l}\text { Patients offered specialist clinic within } \\
12 \text { months (\%) (SD) }\end{array}$ & $78(8)$ & $62-90$ & $21(4)^{\star}$ & $17-27$ \\
\hline
\end{tabular}


Table 4 Multiple logistic regression ORs (and the 95\% $\mathrm{Cl}$ ) examining the likelihood of being offered an appointment within 3 months of the index admission

\begin{tabular}{|c|c|c|c|c|}
\hline & p Value & OR & $\begin{array}{l}\text { Lower } \\
\text { Cl }\end{array}$ & $\begin{array}{l}\text { Upper } \\
\text { Cl }\end{array}$ \\
\hline \multicolumn{5}{|l|}{ Hospital } \\
\hline \multicolumn{5}{|l|}{ Hospital (9) } \\
\hline Hospital (1) & 0.021 & 1.44 & 1.06 & 1.96 \\
\hline Hospital (2) & 0.000 & 1.91 & 1.44 & 2.55 \\
\hline Hospital (3) & 0.000 & 2.08 & 1.55 & 2.81 \\
\hline Hospital (4) & 0.000 & 2.09 & 1.52 & 2.88 \\
\hline Hospital (5) & 0.000 & 2.26 & 1.69 & 3.04 \\
\hline Hospital (6) & 0.000 & 2.69 & 2.02 & 3.59 \\
\hline Hospital (7) & 0.000 & 2.53 & 1.89 & 3.38 \\
\hline Hospital (8) & 0.000 & 3.02 & 2.15 & 4.24 \\
\hline \multicolumn{5}{|l|}{ Quintile } \\
\hline \multicolumn{5}{|l|}{$\begin{array}{l}\text { Quintile } 1 \text { (most } \\
\text { deprived) }\end{array}$} \\
\hline Quintile 2 & 0.079 & 1.16 & 0.984 & 1.36 \\
\hline Quintile 3 & 0.011 & 1.26 & 1.06 & 1.50 \\
\hline Quintile 4 & 0.194 & 1.14 & 0.94 & 1.38 \\
\hline $\begin{array}{l}\text { Quintile } 5 \text { (least } \\
\text { deprived) }\end{array}$ & 0.000 & 1.76 & 1.41 & 2.19 \\
\hline \multicolumn{5}{|l|}{ Age group (years) } \\
\hline$>75$ & 0.000 & & & \\
\hline $55-74$ & 0.000 & 2.65 & 2.09 & 3.35 \\
\hline $35-54$ & 0.000 & 3.45 & 2.74 & 4.36 \\
\hline $16-34$ & 0.000 & 6.27 & 4.92 & 7.99 \\
\hline Male & 0.000 & 0.79 & 0.71 & 0.89 \\
\hline Long stay (>2 days) & 0.031 & 0.88 & 0.78 & 0.99 \\
\hline $\begin{array}{l}\text { Discharge to nursing } \\
\text { home }\end{array}$ & 0.000 & 0.55 & 0.39 & 0.76 \\
\hline $\begin{array}{l}\text { Admission in prior } \\
\text { year }\end{array}$ & 0.000 & 1.33 & 1.19 & 1.49 \\
\hline $\begin{array}{l}\text { Clinic visits in prior } \\
\text { year }\end{array}$ & 0.000 & 4.89 & 4.35 & 5.0 \\
\hline Constant & 0.000 & 0.043 & & \\
\hline
\end{tabular}

home were less likely to have appointments. The patterns noted are the same irrespective of whether the patient attended the clinic.

A multiple logistic regression (table 4) confirmed the univariate picture and provided some quantitation of the interhospital differences. Being part of the clinic system already is a strong predictor of getting another appointment, but more striking is the marked trend for the elderly to not be offered specialist help. The most socially deprived are also relatively excluded.

The regression analyses were also run on group A, and group B separately with very similar results (not presented) save that the age coefficients were a little lower in group A.

Finally the analyses were repeated on 3956/5806 patients $(68 \%)$ in group B, who had had no hospital contact (admission, ED visit, or outpatient clinic) in the prior year, arguing that this subgroup are likely to include a high proportion of 'first fit' patients. Their 3-month clinic appointment rate was similar to the rest of group B patients (11.8\% vs $12 \%$, not significant).

\section{DISCUSSION \\ Principle findings}

These results, using very different methods, echo the findings of the NASH report; ${ }^{3}$ only half $(51 \%)$ of patients admitted were offered neurology appointments, of which only half were attended. Our headlines are that of the $65 \%$ who had not been under specialist review (including the first seizure patients), only $11 \%$ are offered a specialist review within 3 months, and only $2 \%$ within 2 weeks. Less than half of those already known to specialists are seen within 3 months, which is little better than would have happened anyway. We cannot separate how many were first seizures, but can be certain the National Institute for Health and Care Excellence (NICE) 2-week standard ${ }^{2}$ is not being met. Even if some of these patients were being seen as 'ward consults' by visiting neurologists, one would still expect most to be followed-up to assess the effect of treatment changes.

Our choice of the 3 month timeline was pragmatic, based on numbers available to analyse, but is perhaps too long from a patient viewpoint. A seizure admission is a significant event indicating possible new epilepsy or failure of control. Patients should expect to have therapy discussed, and for that to happen in a timely fashion. The low referral patterns are common to all hospitals, and were similarly widespread in $\mathrm{NASH},{ }^{3}$ suggesting this is a generic National Health Service (NHS) problem. It is for others to set the time standards but this is about more than the index admission - as the high readmission and ED attendance rates show.

\section{Strengths and weaknesses}

Could we be misidentifying the seizure cohort at hospital? We have combined an understanding of the hospital coders' rules, and knowledge of the clinical behaviours and organisational pathways, to select out those cases that physicians would have considered to be due to a seizure. Our algorithms exclude those admitted primarily for other conditions where epilepsy is a comorbidity and further specialist referral would be unwarranted. Our algorithmic logic accesses more of the coded information and has been shared with specialists to gain their informal approval both of the algorithms and that the numbers have face validity with experience. This approach towards a clinical interpretation of HES has been now been used across conditions in four major specialties (also respiratory, ${ }^{9}$ gastroenterology ${ }^{10}$ and renal $^{11}$ ) and in each has been shared with the respective specialty physicians and been iteratively improved with their feedback. We believe it is closer to the real-life clinical picture than most other published analyses.

We were reassured that other conditions that might have presented as seizure (cancer, stroke or alcoholism) were only present in modest numbers and so cannot 
explain the low referral rates, although the significant number with alcohol codes does imply a need to triage referrals with care.

The data are reported at admission level since each presentation is an opportunity to intervene. Restricting analysis to only the first admission yields similar conclusions from univariate, and multivariate analyses. This may have future impact if 'referral to specialist' were to become a marker of appropriate care because it is analytically simpler.

\section{What does this imply?}

The data from NASH suggested more could be done, and experience from Ireland showed that early specialist referral reduced 1 year readmissions from $45 \%$ to $9 \%$ and halved 'bed day' use. ${ }^{6}$ These two adjectives are important. Few general physicians or general practitioners are able to keep up with the diagnostic tools and range of treatments now available to manage epilepsy. It has become a specialist area even within neurology. The urgency to refer may be reduced as many seizures will be recovering by the time they are seen in hospital. However, the fact that only $11 \%$ of patients were offered a specialist appointment is almost a 'denial of NHS service' for those patients. For those known to the system a $48 \%$ appointment rate is only marginally higher than should be expected with planned care.

While some epilepsy manifests as repeated seizures despite best therapy, two-thirds of the admissions we identified were not under current specialist review and $89 \%$ were not referred for help. This implies a significant cohort of 'forgotten people.' The regression analysis points to an apparent systematic ageism with referral being particularly unlikely if aged over 75 . There is insufficient clinical information in this data set to investigate the reasons, but it is common to each hospital site and warrants further study. Our cohort had a high readmission rate $(32 \%$ with at least 1 admission in the following 12 months), a mean length of stay of 5 days and many other visits to the ED in the year before and after. If early referral were half as effective as the findings in Ireland, ${ }^{6}$ there would be huge savings for the NHS. But much more important are the benefits of fewer seizure admissions for patients. So why is specialist referral not routine?

\section{Neurology services}

Neurology services operate from regional centres from which specialists visit the acute hospitals. The relationships of visiting specialists to their visited hospitals vary. In a previous study we showed that mortality due to acute kidney injury was very markedly lower when renal specialists were based in the hospital. ${ }^{11}$ The reasons are still being elucidated but it is likely that the specialists' commitment to the acute 'take,' grand rounds and other activities, and the knowledge gained by juniors rotating through the renal wards, has effects on their colleagues that improve the management of issues like fluid balance. Most junior staff have little contact with visiting neurologists and most neurologists have no responsibility to the acute medical take. But to reorganise hospital systems that have been in place for many years without causing chaos elsewhere is not easy. Even the mechanisms for referral into a specialist service are often indirect, depending on primary care to make a decision on appropriateness of referral, with or without a prompt from the discharge letter. But our data show it is not happening for most patients.

This disconnect between service organisation and clinical need has been highlighted in a recent editorial ${ }^{12}$ which strongly advocates that the tertiary neurology units should reach out into the world of acute medicine. But changing clinical pathways requires clinical collaboration across health sectors, but it has to be facilitated by the funders and planners of care. Thus establishing epilepsy clinic capacity so patients can be seen quickly, for example, 2 weeks, requires having enough specialists available and the funding to run those clinics. Moving resources around a healthcare system is never easy but how else is the significant cohort of patients with epilepsy with frequent presentations to hospital going to be enabled to access the specialist services that could help them?

Sharing these data with commissioners and epilepsy specialists in our region has already stimulated two projects to improve the clinical referral pathway. There is a general agreement that 2 or more nights in hospital is unnecessary for most patients-the alternative of discharge with early specialist appointment is likely to be better for, and preferable to, most patients. A very crude estimation is that translating the Irish experience to England would save over 100000 bed days per year. This would make good health and economic sense for the NHS but, more importantly, this group of patients are largely of working age and reducing their seizure (and admission) rates could significantly improve their well-being, their chances of gaining work, and a better quality of social and family life.

\section{Author affiliations}

${ }^{1}$ Department of Data Management, Northwest CSU, Liverpool, UK

${ }^{2}$ Department of Bio-informatics, University of Liverpool, Liverpool, UK

${ }^{3}$ Liverpool CCG, Liverpool, UK

${ }^{4}$ Department of Gastroenterology, University of Liverpool, Liverpool, UK

${ }^{5}$ Aintree University, Hospital NHS Trust, Digestive Diseases Centre,

Liverpool, UK

${ }^{6}$ Department of Medical Statistics, University of Liverpool, Liverpool, UK

Acknowledgements MP, PD and AM acknowledge support from the NIHR Collaboration for Leadership in Applied Health Research and Care North West Coast (CLAHRC NWC).

Contributors MP, PD, AM and TM were involved in the project conception. $\mathrm{RG}, \mathrm{MP}, \mathrm{PD}, \mathrm{KB}, \mathrm{JK}$ and $\mathrm{AM}$ were involved in the methods, analysis and statistical analysis. $R G$ and MP wrote the manuscript with contributions from all the other authors.

Funding This research received no specific grant from any funding agency in the public, commercial or not-for-profit sectors.

Competing interests None declared. 
Ethics approval This project has not used any personal data but has analysed anonymised downloads of NHS records. The outputs will be part of ongoing NHS performance monitoring.

Provenance and peer review Not commissioned; externally peer reviewed.

Data sharing statement Additional data is available by emailing RG; ruth. grainger2@nhs.net.

Open Access This is an Open Access article distributed in accordance with the Creative Commons Attribution Non Commercial (CC BY-NC 4.0) license, which permits others to distribute, remix, adapt, build upon this work noncommercially, and license their derivative works on different terms, provided the original work is properly cited and the use is non-commercial. See: http:// creativecommons.org/licenses/by-nc/4.0/

\section{REFERENCES}

1. Blunt I, Bardsley M, Dixon J. Trends in emergency admissions in England 2004-2009. London: National Audit Office, 2013.

2. NICE. Diagnosis and management of the epilepsies in adults, children and young people. NICE Commissioning Guidelines CMG47, 2013.

3. Dixon PA, Kirkham JJ, Marson AG, et al. National Audit of Seizure Management in Hospitals (NASH): results of the national audit of adult epilepsy in the UK. BMJ Open 2015;5:e007325.
4. The controller and auditor general. Emergency admissions to hospital: managing the demand. London: National Audit Office, 2013.

5. McCormick B, Sam-Hill P. Are hospital services used differently in deprived areas? Evidence to identify commissioning challenges. 2012. http://chseo.org.uk/downloads/wp2-hospitalservicesdeprivedareas.pdf

6. Iyer PM, McNamara PH, Fitzgerald M, et al. A seizure care pathway in the emergency department: preliminary quality and safety improvements. Epilepsy Res Treat 2012;2012:273175.

7. Hospital Episode Statistics. http://www.hesonline.nhs.uk. [Online] HSCIC. 2010.

8. Sundararajan V, Quan $\mathrm{H}$, Halfon $\mathrm{P}$, et al. Cross-national comparative performance of three versions of the ICD10 Charlson Index. Med Care 2007;45:1210-15

9. Walker $\mathrm{P}$, Thompson $\mathrm{E}$, Crone $\mathrm{H}$, et al. Use of mortality within 30 days of a COPD hospitalisation as a measure of COPD care in UK hospitals. Thorax 2013;68:968-70.

10. Shawihdi M, Thompson E, Kapoor N, et al. Variation in gastroscopy rate in English general practice and outcome for oesophago-gastric cancer: retrospective analysis of hospital episode statistics. Gut 2014:63:250-61.

11. Abraham KA, Thompson EB, Bodger $\mathrm{K}$, et al. Inequalities in outcomes of acute kidney injury in England. QJM 2012;105: 729-40.

12. Morrish PK. Inadequate neurology services undermine patient care in the UK. BMJ 2015;350:h3284. 


\section{Correction}

Grainger R, Pearson M, Dixon P, et al. Referral patterns after a seizure admission in an English region: an opportunity for effective intervention? An observational study of routine hospital data. BMJ Open 2016;6:e010100.

In the abstract the third sentence of the results section states:

"Subsequent attendance at a specialist clinic is more likely if already known to a clinic, if aged $<35$ years, if female, or required a longer spell in hospital."

The word longer should have been shorter. The regression is correct in the main body of text and table.

In addition, tables 2 and 3 include different legends and footnotes (correctly) but contain identical data. The data from table 2 appears twice. The correct data for table 3 is given below.

Table 3 Comparison of patients according to whether or not they were offered a clinic appointment within 3 months (whole cohort - rather than inter-hospital differences)

\begin{tabular}{|c|c|c|c|c|}
\hline & \multicolumn{2}{|c|}{$\begin{array}{l}\text { GROUP A: Patients "known" to } \\
\text { the specialist team }(n=3066)\end{array}$} & \multicolumn{2}{|c|}{$\begin{array}{l}\text { Group B: Patients who are new } \\
\text { or not under follow-up } \\
(n=5806)\end{array}$} \\
\hline & $\begin{array}{l}\text { Not offered } \\
\text { neurology } \\
\text { clinic } \\
\text { appointment }\end{array}$ & $\begin{array}{l}\text { Offered } \\
\text { neurology } \\
\text { clinic } \\
\text { appointment }\end{array}$ & $\begin{array}{l}\text { Not offered } \\
\text { neurology } \\
\text { clinic } \\
\text { appointment }\end{array}$ & $\begin{array}{l}\text { Offered } \\
\text { neurology } \\
\text { clinic } \\
\text { appointment }\end{array}$ \\
\hline Number of patients (\% of group) & $1621(53 \%)$ & 1445 (47\%) & $5153(89 \%)$ & $653(11 \%)$ \\
\hline DNA rate at the given clinic (\%) & $\mathrm{n} / \mathrm{a}$ & 14.3 & $\mathrm{n} / \mathrm{a}$ & 11.5 \\
\hline Number of patients actually seen (\% of group) & $\mathrm{n} / \mathrm{a}$ & $1238(40 \%)$ & $\mathrm{n} / \mathrm{a}$ & $581(10 \%)$ \\
\hline Co-morbidity ( $\%$ with Charlson score $\geq 1$ ) & $123(7.6 \%)$ & $75(5.2 \%)$ & $904(17.5 \%)$ & $65(10 \%)$ \\
\hline Mean age (years $(\mathrm{SD})$ ) & $49.2(17.3)$ & $43.7(16.6)$ & $60.7(19.7)$ & $47.3(18.4)$ \\
\hline Sex (\% male) & 57.6 & 53.1 & 55 & 53.6 \\
\hline Mean Length of Stay (days) & 5.3 & 3.9 & 6.5 & 3.8 \\
\hline Mean IMD rank & 9545 & 10025 & 11279 & 11466 \\
\hline Mean number of ED visits in prior year & 3.4 & 3.8 & 2.6 & 2.4 \\
\hline Mean readmission rate in the year after & $38.4 \%$ & $48.5 \%$ & $30.1 \%$ & $35.0 \%$ \\
\hline Mean number of ED visits in the year after & 3.4 & 2.9 & 2.0 & 2.2 \\
\hline Discharged to nursing home (\%) & 4.4 & 2.4 & 9.8 & 2.8 \\
\hline
\end{tabular}

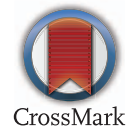

